\title{
Leveraging the Promotion of Tourist Destinations and the Interpretation of their Heritage using Virtual Reality
}

\author{
Carlos R. CUNHA ${ }^{1}$, Vítor MENDONÇA ${ }^{2}$, João Pedro GOMES ${ }^{3}$, Elisabete \\ Paulo MORAIS ${ }^{4}$ and André MOREIRA ${ }^{5}$ \\ 1,4UNIAG; Instituto Politécnico de Bragança, Campus de Santa Apolónia, \\ 5300-253 Bragança, Portugal \\ 2,3,5Instituto Politécnico de Bragança, Campus de Santa Apolónia, 5300-253 Bragança, \\ Portugal
}

Correspondence should be addressed to: Carlos R. CUNHA; crc@ipb.pt

Received date:11 May 2021; Accepted date: 29 October 2021; Published date: 7 Fdebruary 2022

Academic Editor: Fábio Longo de Moura

Copyright (C) 2022. Carlos R. CUNHA, Vítor MENDONÇA, João Pedro GOMES, Elisabete Paulo MORAIS and André MOREIRA. Distributed under Creative Commons Attribution 4.0 International CC-BY 4.0

\begin{abstract}
Technology is increasingly a transversal layer to all activities and, in this sense, exploring the potential of technology as a driver to support the competitiveness of organizations and nations has become a necessity for survival. Tourism is a fundamental asset in many modern economies and certainly fundamental from a civilizational and generational point of view, insofar as associated with a wide range of tourist destinations is its heritage. As such, the promotion and interpretation of destinations and their heritage are very important and, in these areas, technologies have played a fundamental and revolutionary role. In this scenario, Virtual Reality, among other technologies, demonstrates a vast potential in promoting tourist destinations and in creating immersive experiences that allow for a better interpretation of destinations and their heritage, as well as greater attractiveness for younger generations. This article, after a review of technological concepts and a discussion of their role in the context of tourism and heritage, proposes a conceptual model capable of contributing to a more agile and massified creation of Virtual Reality experiences. Finally, an experimental prototype created for an olive and olive-oil museum is presented, with the aim of facilitating the interpretation, by visitors, of its permanent exhibition objects and improving the visiting experience.
\end{abstract}

Keywords: Virtual Reality, Conceptual Model, Tourism, Heritage, Prototype

Cite this Article as: Carlos R. CUNHA, Vítor MENDONÇA, João Pedro GOMES, Elisabete Paulo MORAIS and André MOREIRA (2022)," Leveraging the Promotion of Tourist Destinations and the Interpretation of their Heritage using Virtual Reality", Journal of Innovation \& Business Best Practice, Vol. 2022 (2022), Article ID 629340, DOI:10.5171/2022.629340 


\section{Introduction}

Tourism has gained an increasing economic role in most regions worldwide, being one of the sectors that most contributes to the socio-economic development of the regions, considering that tourism can involve a plurality of other economic sectors. Tourism products can include; urban tourism, seaside tourism, rural tourism, ecotourism, wine tourism, culinary tourism, health tourism, medical tourism, religious tourism, cultural (or heritage) tourism, sports tourism, educational tourism, business tourism, among others (Camilleri, 2018).

However, the success of tourism is increasingly dependent on information and communication technologies, which can and should be a lever to facilitate and enrich the experiences of tourists. We can affirm that the Information Technologies can induce the obtaining of competitive advantages (Bethapudi, 2013; Vidas-Bubanja \& Bubanja, 2017).

The powerful capabilities of Tourism technologies allow for the enhancement of interaction with a system and enrichment of the tourist experience itself, providing new ways of assisting in behavior change and even in the long-lasting transformation of the users (Stankov \& Gretzel, 2020).

In this context, it is not enough to resort to mere web sites, videos on the YouTube platform, or posts on social networks. It is essential to develop immersive technological platforms geared towards the tourist experience that contribute to enriching the experience and, therefore, increasing the satisfaction of tourists.

We must consider that the tourist experience can be subdivided into three major moments: the before, the during, and the after. In a first moment (the before), the focus will be on arousing the interest of the tourist and making them want to visit; in a second moment (during), it should support the tourist experience by contributing immersive content that complements the visit (e.g., legends, historical videos); lastly (the after), it will be essential to maintain the interest of the tourist and captivate them to revisit.

Therefore, systems that encourage transformative effects are anchored in human centering by default and provide stimuli that stimulate the desired welfare results in addition to the use of the system or tourism experience purposes (Stankov \& Gretzel, 2020). Virtual Reality (VR) systems must be seen as a paradigm that contributes effectively to this purpose.

VR technology uses a computer to create a more realistic virtual environment, combined with the auxiliary functions of different detection equipment, so that the user is completely immersed in the generated virtual environment, and then interacts with the virtual environment through the man-machine interface, so that the user will have a kind of illusion like the illusion that the user is in in the real world (Tian, 2021).

Although some experiences using VR have been developed in recent years, the paradigm is not yet fully matured so that it can be adopted by most organizations in the tourism sector and that the materialization of these types of projects, generally, implies a high financial cost. In this sense, this article contributes to the proposal of a model that can be adopted for the development of VR systems to promote tourist destinations.

This paper is structured as follows: First, we review literature on VR and its applications on tourism scenarios. Next, we present and describe a conceptual model to support the development of VR systems for the tourism sector and an experimental prototype developed to an olive oil museum. Finally, a conclusion is made about VR drive solutions in tourism.

\section{Virtual Reality, Tourism and Heritage}

The use of VR can leverage tourism in its various aspects. The process of dematerialization of tourist promotion materials, and of supporting the 
interpretation of heritage, is a growing challenge. Arranging innovative ways of promoting tourist destinations and helping tourists in their interpretation experience must be an imperative of all entities related to tourism. In this domain, VR, along with other technologies, has a primary role in that it supports the creation of innovative experiences of promotion (i.e., the before), support (i.e., the during) and memorization (i.e., in the after) of a given trip / tourist experience - by the ability of virtually revisiting the destination experience.

According to Loureiro, Guerreiro, \& Ali (2020), VR, in addition to Augmented Reality (AR), have undergone several technical developments in recent decades, including several improvements in the ability to provide immersive experiences and the telepresence sensation, with several examples of applications of such techniques in stores, tourism, hotels and destinations. VR has contributed to the development of the tourism sector, providing experiences of real and unreal situations, allowing innovative ways to explore information, travel, enjoyment, well-being and analysis of tourist destinations (Kim, Lee, \& Preis, 2020). Also, heritage-centered tourism faces the problem of the deterioration of its artefacts which have added to them the cost of preserving and managing that heritage. In this context, the use of VR can leverage the creation of tourist experiences in destinations and places that have succumbed to excessive tourism, resulting deterioration and even destruction (Bec, Moyle, Schaffer, \& Timms, 2021).

According to Bogicevic, Seo, Kandampully, Liu, \& Rudd (2019), a visualization of VR induces a greater elaboration of mental images about the experience and a strong sense of presence, translating into a marked and improved experience, and in this way, the VR will enhance a feeling of "almost dream" of a given offer even before it is actually experienced at the destination. This view is corroborated by Kang (2020), who has studied the impact of VR on the impulsive desire of a destination, concluded that the use of VR (and its telepresence effect) increases the perceived knowledge, reduced the perceived risk and increases the impulsive desire through the triggered cognitive process, producing a strong effect on a tourist product. Also, the study by Yung, Khoo-Lattimore, \& Potter (2021), with the objective of investigating the effectiveness of VR as a tourism marketing tool through presence and emotion, concluded that the introduction of VR into the marketing mix, especially for trend-based travel, can provide a greater level of effectiveness in the ability to guide behavioral intention.

Regarding heritage, VR may have a very important role to innovate in the way that citizens can know, interpret, and interact with heritage. In this domain, there are several challenges and uses. The explosion of tourism in the last decades, driven by the greater ease in making trips of medium / long distance, and by the increase of financial capacity, did not translate into a complete democratization in the access to tourist experiences and, in a Human perspective, to the right to know the civilizational heritage. If it is certain that in the life of each citizen, there will be no possibility for them to visit and enjoy the entire civilizational heritage; this fact may be lessened by the ability to enjoy it virtually in the most immersive way possible. In this regard, VR plays a very important role.

In this domain, several projects have been developed. In Bozzelli et al. (2019) is presented the ArkaeVision project, an integrated system centered on the user, that is capable of offering different modalities of exploitation of Heritage assets, such as virtual representations of monuments and works of art, as well as the stories associated with those objects. Arrighi, See, \& Jones, (2021) presented a study centered on the digital reconstruction of a historic building - the Victoria Theater in Newcastle, Australia. This VR project, called "Visualizing the Victoria", focuses on mechanisms to preserve the heritage of this site. In Lee, Kim, Ahn, \& Woo (2019) is used VR focused on contextual risk management for architectural heritage. Rua \& Alvito (2011), after a process of building 3D models, used a VR game engine to create an ambience of the Roman villa of Casal de Freiria, allowing a complete exploration of 
space. Hajirasouli, Banihashemi, Kumarasuriyar, Talebi, \& Tabadkani (2021) present an immersive 360-degree VR experience, designed for the village of Kandovan.

VR has an undeniable potential in the promotion of destinations and, more specifically, in the promotion of heritage, especially when that heritage is very degraded or almost nonexistent contributing to the preservation of the historical legacy of civilizations between generations.

A VR-based conceptual model is presented in the next chapter, to contribute to leveraging the adoption of VR, to promote the conversion of traditional multimedia content into new VR experiences, allowing visitors to better understand their potential destinations of choice, and / or a better fruition of touristic experiences and the interpretation of the territories.

\section{Conceptual Model}

In view of the technological evolution in the scope of VR that has been materialized in recent years, we consider it opportune to develop facilitating technological systems, which allow organizations to adopt this technological paradigm to implement strategies that induce opportunities, as may be the case of providing virtual experiences in the tourism sector to communicate and publicize tourist destinations (Stankov \& Gretzel, 2020).

The conceptual model that we present in figure 1 summarizes the elements that should be considered for the development of a VR system.

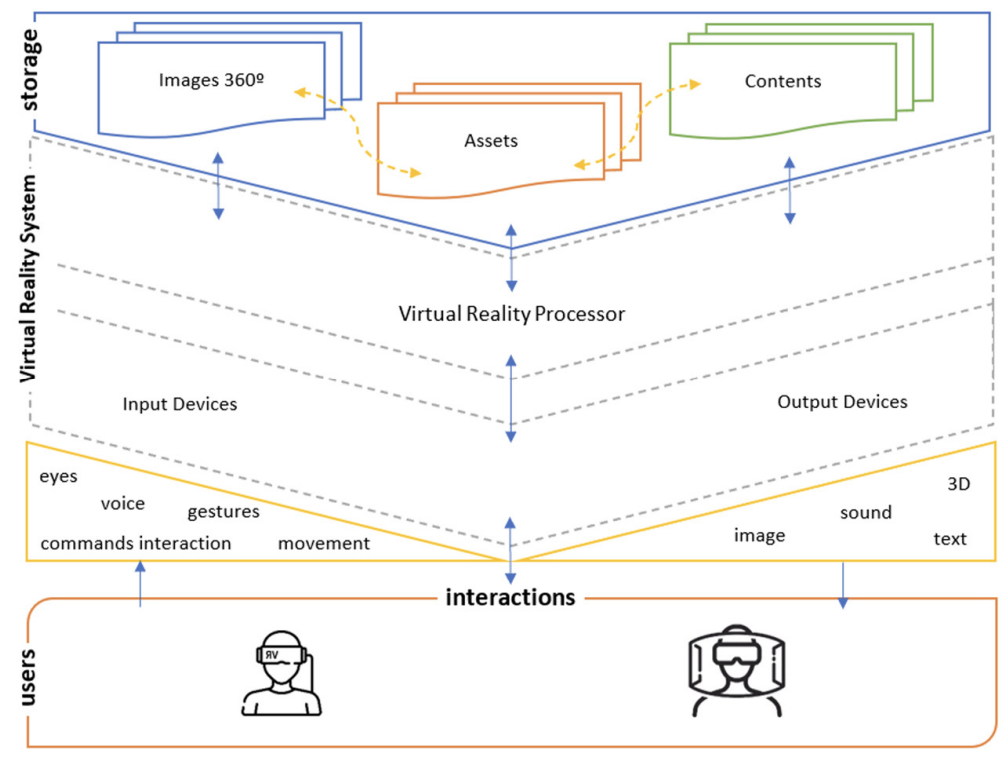

Fig. 1. Virtual Reality Conceptual Model

According to the presented model, a VR system will be based on the storage of $360^{\circ}$ images and content mapping. This will imply to signal interactive elements (assets) and link complementary contents (e.g., text, sound, video, 3D) that allow the user to experience different content formats.
In this context, the storage layer should provide the necessary resources to effectively store the different types of content, as well as their indexing and mapping. To this end, it will be possible to use cloud services, ensuring mass storage capacity and high speeds of information traffic. 
The use of $360^{\circ}$ images is the essential support in the VR paradigm, which should allow a realistic view of virtual environments. Thus, it will be necessary to have several panoramic $360^{\circ}$ images of each of the environments (e.g., city, museum, monument). The mapping of the interactive elements is done using the indexing of "Assets" in each $360^{\circ}$ image and linking the contents that will be displayed before a given interaction.

The VR processor layer is responsible for interpreting the interactions captured by the input devices (e.g., eye tracking that detects eye movement, microphone that captures audio orders, the video camera that detects hand gestures or the gyroscope that detects rotation).

We should consider that the experience in VR will be as rewarding for users as the quality of the contents made available (Chen, Jin, Goodall, Yu, \& Bovik, 2019; Jiang, Yang, Jiang, Lv, \& Meng, 2018), as well as the ease of interaction that the system provides (Murthy, 2020).

The following use case diagram, figure 2, illustrates in a simplified way the functionalities of the application developed to allow the user to enjoy a VR experience.

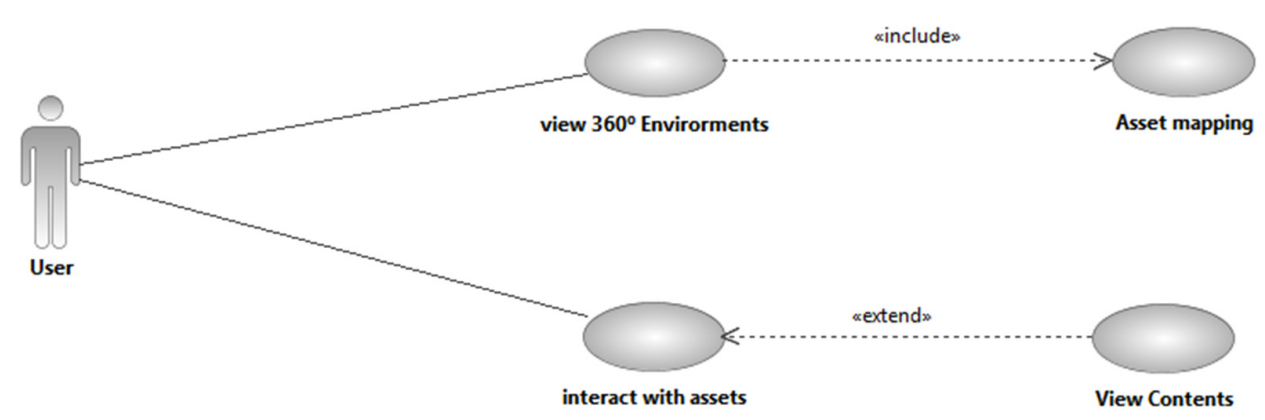

Fig. 2. Use Case Diagram of Virtual Reality Experience

As illustrated, users will be able to view and navigate in $360^{\circ}$ environments, which present mapped "assets", which, in turn, allow interactions to access different content.
Figure 3 summarizes different types of interactions that should be present in a VR application, noting that the increase in interaction forms promotes greater inclusion and immersiveness. 


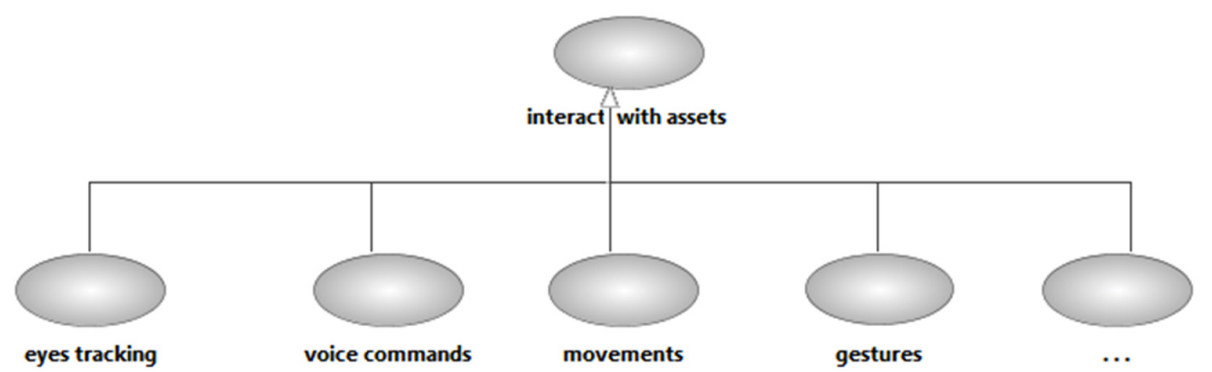

Fig. 3. Use Case Diagram of generalization of interaction types

On the other hand, the interaction with the "assets" allows the user to enjoy content, which may be diverse and complementary to enrich their virtual experience, thus, and according to figure 4, users will be able to read texts, see images, listen to audios, watch videos, among others.

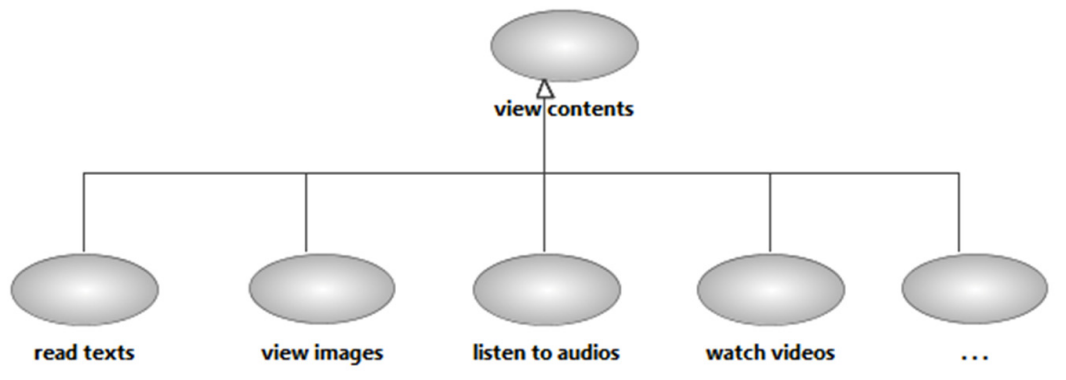

Fig. 4. Use Case Diagram of generalization of contents fruition

Thus, a VR system should provide several forms of interaction and that can work in a complementary way to streamline interactivity. For example, it will be possible to combine a voice order with eye tracking, that is, when the user looks at a certain
"Asset", they will be able to execute a voice order to open complementary content.

In a schematic way, an example of an interaction in a VR experience is outlined in figure 5 .

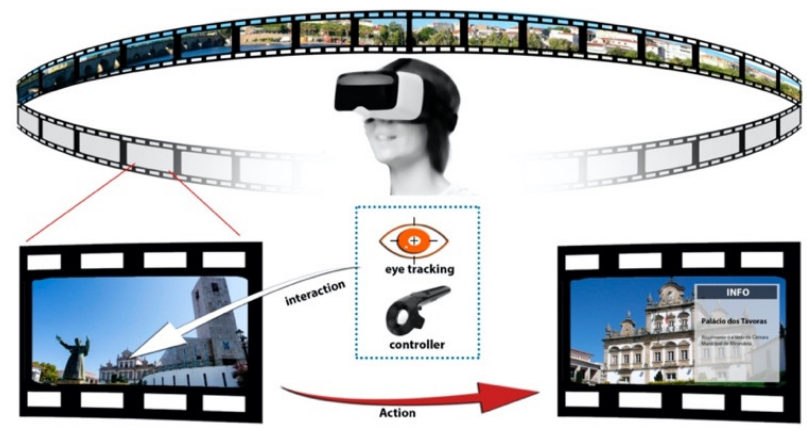

Fig. 5. Virtual Reality Experience 
For example, an "Asset" of a monument may allow the user to view descriptive textual information about the monument or even view a video of a virtual tour from inside.

It should be noted that the system should provide its users with multiple forms of interaction, and for that it should include different sensors, as well as being able to provide multiple types of content. Thus, and as an example, users will be able to interact with the system using gestures, voice, movement, eye tracking, among others. The interaction can be with the virtual environment (360 panoramic images) or manipulating the content (e.g., rotating a 3D object, swapping text, play or pause video).

\section{An Experimental Developed Prototype to an Olive Oil Museum}

To carry out experiments with the use of VR to allow the promotion of heritage, an experimental prototype was developed based on an olive oil museum in a city in the northeast of Portugal - where olive oil production is a very strong cultural landmark - a reason that led to the recent creation of a thematic museum. Additionally, the creation of the prototype allowed to carry out a set of preliminary experiments based on the conceptual model proposed in the previous chapter.

In a nutshell, the aforementioned olive oil museum's mission is to disseminate the material and immaterial heritage associated with all stages of the olive oil production process, as well as the various uses of this unique product, in the present and in the past (e.g., lighting, hygiene products such as soap). In order to fulfill its mission, the museum has a permanent exhibition of several objects associated with the olive oil production process, as well as several items associated with its use and manipulation (e.g., oil lamp).

\section{Prototype Goals}

Within the objectives defined for the prototype, were the mapping of the space using $360^{\circ}$ images and the generation of content associated with the objects exhibited in the museum. In this way, the visitor could obtain more information about the objects as well as understand the role of each object used in the olive oil production process. As this theme is associated with immaterial patronage (e.g., singing, ancestral techniques), cultural contents associated with these objects were also coupled. In this way, we were able to improve the interpretation, enjoyment, and even the visualization of certain traditions that no longer exist in the current modern olive oil production process - (re) living an authentic cultural experience.

\section{Technical Development Specifications}

The prototype developed used the VR equipment HTC $\AA$ VIVE $\AA$ Pro EYE full kit (figure 6), operating on a computer with an Intel $\AA$ Core $^{\mathrm{TM}}$ i7-10700KF processor with 32 GB of RAM and an NVIDIA $\AA$ GeForce $\AA$ RTX 2070 SUPER ${ }^{\mathrm{TM}}$ graphics card. 

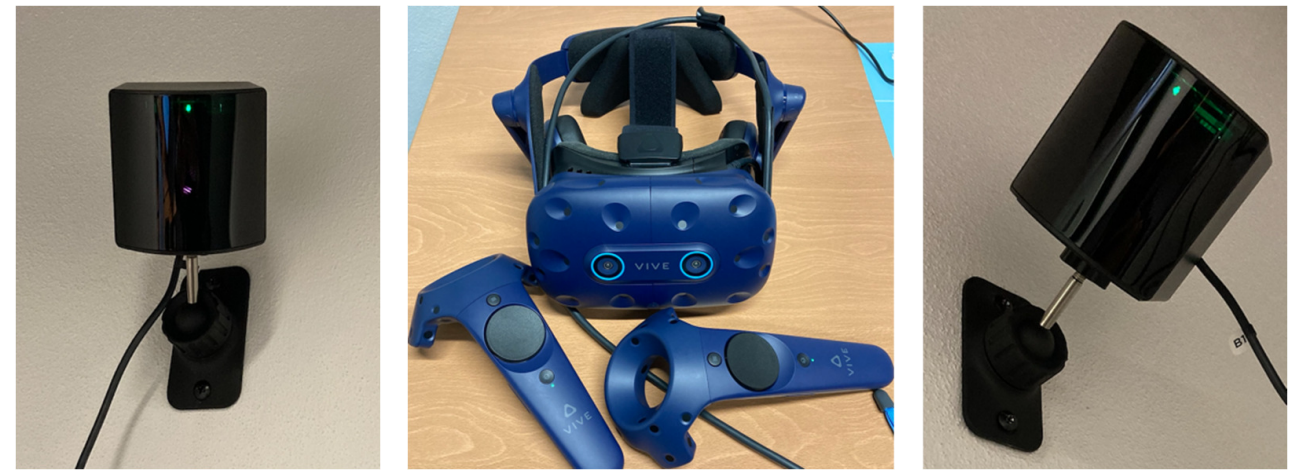

Fig. 6. HTC@ VIVE® Pro EYE full kit

Regarding the programming of the experimental scenario and integration of assets, the Unity game engine was used along with the C\# programming language. For the creation of $360^{\circ}$ images, a Xiaomi Mi Sphere camera was used.

\section{Development Process and Results Achieved}

The development process started with the capture of $360^{\circ}$ images of the different spaces of the museum. In this way, the areas and objects on display were mapped. An example is illustrated in figure 7. In parallel to this phase, the multimedia contents to be indexed to each object in the museum were compiled and the dynamics of interaction between the user and the different objects designed.

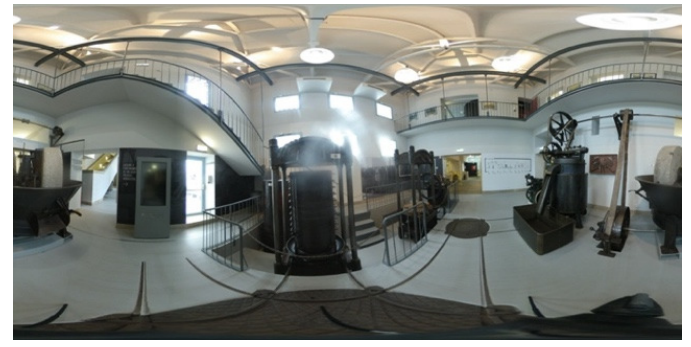

Fig. 7. Example of a $360^{\circ}$ photography of an exhibition museum space hall

The objects of the museum were mapped through the inclusion of small assets that allow the user to perceive that there is information available indexed to the object. In this way, multimedia content is made available that allowed the user to understand the object's usefulness, in the context of the olive oil production process, as well as to understand the object's functioning and its evolution over time. Some of the objects displayed by the museum are already obsolete; this fact alerts us to the fact that new generations tend not to be able to identify these objects, much less to understand their purpose. Leveraging the ability to pass on ancestral traditions and their tools from generation to generation is extremely important for the perpetuation of the patrimonial legacy. With the use of VR, we can educate about the old through fun technologies and interaction mechanisms that are appropriate to the interests of the new generations. In figure 8 is illustrated an asset mapping an old motorized stone grinding, to grind olives and the consequent association of a pop-up window with information that explains the object's functionality.

The interaction with the system can be performed through the use of hand controllers or through eye tracking 
(supported by the VR equipment). In this way, interaction mechanisms are simple and highly usable, even for people with some special motor needs.

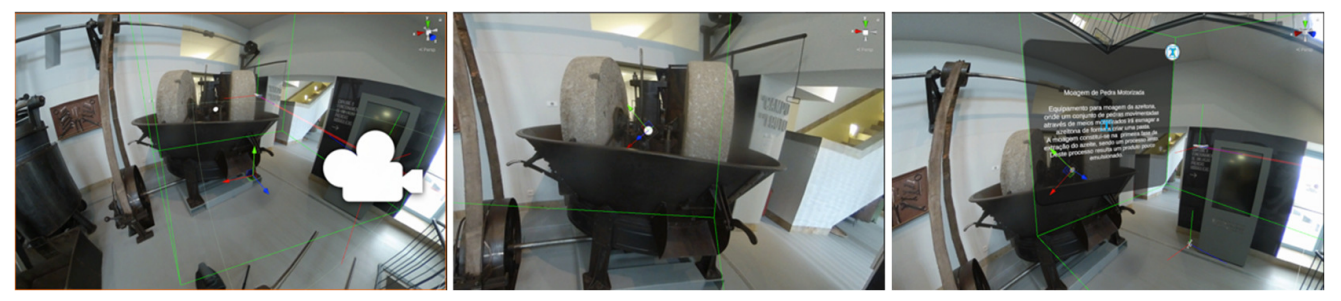

Fig. 8. Inclusion of an asset-marking point with a pop-up information window

In figure 9 is illustrated a user in a physical environment outside the olive oil museum testing the developed VR environment - traversing the virtualized space and accessing content mapped through the assets included in the objects.

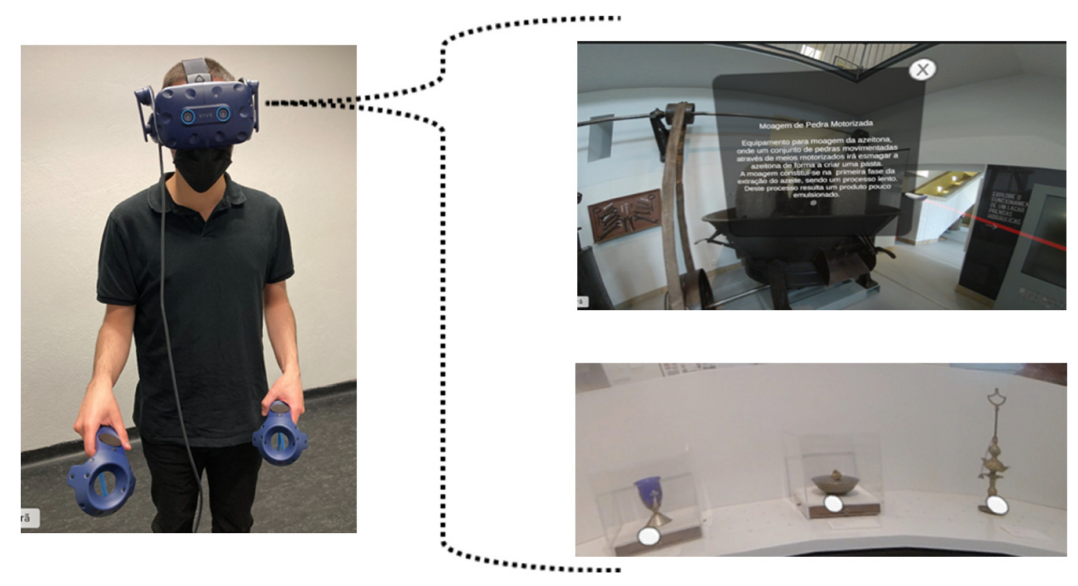

Fig. 9. Experiencing the developed prototype, examples.

This experimental prototype is still in a development phase, with content being implemented only for part of the objects existing in the olive oil museum. The future work intends to test, validate and include increased levels of immersiveness. The evaluation of the prototype by a test population, external to the development team, will also be carried out in the near future.

\section{Conclusion}

Technology has revolutionized the tourism sector. Accordingly, the three moments of a trip - the before, the during, and the after, have been populated by many solutions that aim to inform and help travelers. The world population contains a generational mix where, more and more, "digital natives" demand innovative solutions tailored to their needs and digital vision.

The VR, with which many of today's adults were born, has a primary role in the ability to create immersive experiences and a greater ability to allow an adequate understanding of tourist destinations, interpretation of heritage and future memorization of lived experiences. 
This article reflects on the role of technologies and particularly the role of VR in the context of tourism and heritage, proposing a conceptual model and an experimental prototype based on VR. In this way, it translates into a contribution to a reengineering of the current content production paradigm which, due to several factors (which are not the target of this work), is still too based on a digitization of the image of physical materials and still far from what we believe they should be - new digital content. However, current and future citizens / tourists will be increasingly demanding when it comes to the mechanisms available, so we believe that each time planning a tourist experience will be based more and more on the maxim "Visiting a destination that we know and that knows us".

\section{Acknowledgments}

UNIAG, R\&D unit funded by the FCT Portuguese Foundation for the Development of Science and Technology, Ministry of Science, Technology and Higher Education. UIDB/04752/2020

\section{References}

- $\quad$ Arrighi, G., See, Z. S., \& Jones, D. (2021). Victoria Theatre virtual reality: A digital heritage case study and user experience design. Digital Applications in Archaeology and Cultural Heritage, 21, e00176.

https://doi.org/10.1016/j.daach.2021. e00176

- $\quad$ Bec, A., Moyle, B., Schaffer, V., \& Timms, K. (2021). Virtual reality and mixed reality for second chance tourism. Tourism Management, 83, 104256. https://doi.org/10.1016/j.tourman.20 20.104256

- Bethapudi, A. (2013). the Role of Ict in Tourism Industry. Journal of Applied Economics and Business, 1(4), 67-79. http://www.aebjournal.org/articles/0 104/010406.pd

- $\quad$ Bogicevic, V., Seo, S., Kandampully, J. A., Liu, S. Q., \& Rudd, N. A. (2019). Virtual reality presence as a preamble of tourism experience: The role of mental imagery. Tourism Management, 74, 55-
64.

https://doi.org/10.1016/j.tourman.20 19.02.009

- Bozzelli, G., Raia, A., Ricciardi, S., De Nino, M., Barile, N., Perrella, M., ... Palombini, A. (2019). An integrated VR/AR framework for user-centric interactive experience of cultural heritage: The ArkaeVision project. Digital Applications in Archaeology and Cultural Heritage, 15, e00124. https://doi.org/10.1016/j.daach.2019. e00124

- Camilleri, M. A. (2018). The Tourism Industry: An Overview. 3-27. https://doi.org/10.1007/978-3-31949849-2_1

- $\quad$ Chen, M., Jin, Y., Goodall, T., Yu, X., \& Bovik, A. C. (2019). Study of 3D Virtual Reality Picture Quality. IEEE Journal on Selected Topics in Signal Processing, $\mathrm{PP}(\mathrm{c})$,

1. https://doi.org/10.1109/JSTSP.2019.2 956408

- D, M. L. R. (2020). Multimodal Interaction for Real and Virtual Environments. In Proceedings of the 25th International Conference on Intelligent User Interfaces Companion (pp. 29-30). New York, NY, USA: Association for Computing Machinery. https://doi.org/10.1145/3379336.338 1506

- Hajirasouli, A., Banihashemi, S., Kumarasuriyar, A., Talebi, S., \& Tabadkani, A. (2021). Virtual realitybased digitisation for endangered heritage sites: Theoretical framework and application. Journal of Cultural Heritage. https://doi.org/10.1016/j.culher.2021. 02.005

- Jiang, B., Yang, J., Jiang, N., Lv, Z., \& Meng, Q. (2018). Quality assessment for virtual reality technology based on real scene. Neural Computing and Applications, 29(5), 1199-1208. https://doi.org/10.1007/s00521-0162828-0

- Kang, H. (2020). Impact of VR on impulsive desire for a destination. Journal of Hospitality and Tourism Management, 42, 244-255. https://doi.org/10.1016/j.jhtm.2020.0 2.003 
- Kim, M. J., Lee, C.-K., \& Preis, M. W. (2020). The impact of innovation and gratification on authentic experience, subjective well-being, and behavioral intention in tourism virtual reality: The moderating role of technology readiness. Telematics and Informatics, 49, 101349. https://doi.org/10.1016/j.tele.2020.10 1349

- $\quad$ Lee, J., Kim, J., Ahn, J., \& Woo, W. (2019). Context-aware risk management for architectural heritage using historic building information modeling and virtual reality. Journal of Cultural Heritage, 38, 242-252. https://doi.org/10.1016/j.culher.2018. 12.010

- $\quad$ Loureiro, S. M. C., Guerreiro, J., \& Ali, F. (2020). 20 years of research on virtual reality and augmented reality in tourism context: A text-mining approach. Tourism Management, 77, 104028.

https://doi.org/10.1016/j.tourman.20 19.104028

- Murthy, L. R. D. (2020). Multimodal interaction for real and virtual environments. Proceedings of the 25 th International Conference on Intelligent User Interfaces Companion, 29-30. https://doi.org/10.1145/3379336.338 1506
- Rua, H., \& Alvito, P. (2011). Living the past: 3D models, virtual reality and game engines as tools for supporting archaeology and the reconstruction of cultural heritage - the case-study of the Roman villa of Casal de Freiria. Journal of Archaeological Science, 38(12), 3296-3308.

https://doi.org/10.1016/j.jas.2011.07. 015

- Stankov, U., \& Gretzel, U. (2020). Tourism 4.0 technologies and tourist experiences: a human-centered design perspective. Information Technology \& Tourism, 22(3), 477-488. https://doi.org/10.1007/s40558-02000186-y

- Tian, F. (2021). Immersive 5G Virtual Reality Visualization Display System Based on Big-Data Digital City Technology. 2021.

- Vidas-Bubanja, M., \& Bubanja, I. (2017). The importance of ICT for the competitiveness of tourism companies. TISC-Tourism International Scientific Conference Vrnjačka Banja, 470-489.

- Yung, R., Khoo-Lattimore, C., \& Potter, L. E. (2021). VR the world: Experimenting with emotion and presence for tourism marketing. Journal of Hospitality and Tourism Management, 46, 160-171. https://doi.org/10.1016/j.jhtm.2020.1 1.009

Carlos R. CUNHA, Vítor MENDONÇA, João Pedro GOMES, Elisabete Paulo MORAIS and André MOREIRA, Journal of Innovation \& Business Best Practice, DOI: 10.5171/2022.629340 